Plant Tissue Cult. \& Biotech. 30(2): 285-295, 2020 (December)

CBangladesh Assoc. for Plant Tissue Culture \& Biotechnology

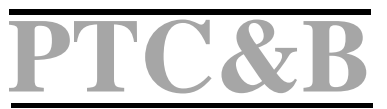

\title{
Effects of Media composition on Asymbiotic Seed Culture of Vanda tessellata: An Approach to In vitro Conservation
}

\author{
Sumana Aditya, Tustu Mondal ${ }^{1}$ and Nirmalya Banerjee*
}

Laboratory of Cytogenetics and Plant Biotechnology, Department of Botany, Visva-Bharati, Santiniketan-731235, West Bengal, India

Keywords: Asymbiotic seed culture, Protocorms, Vanda, In vitro conservation

\begin{abstract}
For initiation of seed germination and protocorm growth in Vanda tessellata (Roxb.) Hook. ex G. Don different media, namely Knudson's C basal medium, modified Knudson's $C$ basal medium, Murashige and Skoog basal medium, Vacin and Went basal medium and Lindeman basal medium either alone or supplemented with vitamin or $0.1 \%$ peptone $(\mathrm{w} / \mathrm{N})$ were used. Vitamin mixture was consisted of nicotinic acid, pyridoxine and thiamine $\mathrm{HCl}$ at $1: 1: 10$, respectively. For the initiation of germination, all the treatments exhibited promising results without showing significant variation. But the rate of survival of the germinated seedlings was remarkably low in all the basal media. Maximum survival rate of germinated seedlings was recorded in MS $+0.1 \%$ peptone. Necrosis of protocorms was a common phenomenon in all the treatments and $100 \%$ necrosis was recorded in LM basal medium and LM + vitamin. Addition of vitamin mixture and peptone in the basal media increased the rate of survival as well as differentiation of the germinated protocorms. Maximum rooted plantlets were recorded in $\mathrm{VW}+0.1 \%$ peptone.
\end{abstract}

\section{Introduction}

Orchidaceae is comprised of one of the most popular ornamental crops for the mesmerizing beauty of the flowers with long shelf lives and occasionally for the fragrance (Roy and Banerjee 2002). Depending upon the current demand, they are commercially utilized as cut flowers as well as potted plants.

However, there are some difficulties in propagation of orchids through conventional methods as it possesses very complex and unique characteristics in its flowers which

*Author for correspondence: <nirmalya.banerjee54@gmail.com>. ${ }^{1}$ Department of Biotechnology, St. Xavier's College, Burdwan-713103, India.

DOI: https://doi.org/10.3329/ptcb.v30i2.50698 
slows the rate of successful pollination by natural means. Even after successful pollination, germination of seeds depends on its specific mycorrhizal partner. Due to this constraint, hardly $5 \%$ seeds germinate in nature at a slow rate. Due to these reasons, nowadays the horticultural industry mostly depends on in vitro techniques for commercial production of ornamental orchids (Mukhopadhyay and Roy 1994, Suttle 1996). Apart from its horticultural values, many orchids are medicinally important and as such orchids are indiscriminately exploited in nature. In addition unauthorized trade and collection of orchids by orchid lovers, the rare and precious orchid species are disappearing day by day. This is an indication of extinction of these orchid species (Abraham et al. 2012). To save the valuable orchid germplasm from extinction, at present in vitro clonal propagation particularly the asymbiotic seed germination technique is being practiced (Arditti 1967, 1979, 1982, Arditti et al. 1981, Thompson et al. 2006, Kauth et al. 2006, Steward and Kane 2006).

Vanda tessellata (Roxb.) Hook. ex G. Don. is an epiphytic orchid which is wildly distributed throughout the sub Himalayan tract to peninsular India and Sri Lanka (Roy and Banerjee 2002). This species is highly important for its medicinal properties. The whole plant body is used in Ayurvedic medicines. Paste of leaves is used in fever. It is the ingredient of 'Rasna Panchaka Quatha', the Ayurvedic formulation used in treatment of arthritis and rheumatism (Singh and Duggal 2009). Apart from this, a novel aphrodisiac compound has been isolated from the flower of $V$. tessellata which activates neuronal (nNOS) and endothelial nitric oxide synthase (eNOS) that influences the levels of nitric oxide (NO) in tissue and blood (Subramonium et al. 2013). The wild population of $V$. tessellata has been reduced drastically due to its high economic importance, overexploitation, habitat deterioration and heavy deforestation of host trees (Pandey et al. 2003). Therefore, this orchid has been designated as an endangered species in India (Prakash et al. 2013a,b; Bhattacharjee and Islam 2014). International Union for Conservation of Nature (IUCN) ranked $V$. tessellata as conservation prioritized orchid species with decreasing population and has recommended for its ex situ conservation (Khela and Chadburn 2014).

In this study, suitable culture media were standardized using five basal media for in vitro asymbiotic seed germination, protocorm growth and their morphogenesis in the presence of vitamins and organic supplements. Asymbiotic seed culture under aseptic condition is the ideal method for conservation and propagation of orchids in general (Rasmussen 1995). Therefore, a fruitful initiative was undertaken to optimize the asymbiotic seed culture of $V$. tessellata using vitamin and organic supplements followed by the detailed study of the growth and morphogenesis of seedlings and protocorms.

\section{Materials and Methods}

Aseptic culture was initiated from the seeds of Vanda tessellata (Roxb.) Hook. ex G. Don collected from 9-month-old undehisced mature capsules raised through manual self- 
pollination method. The freshly collected capsules were first thoroughly washed with liquid detergent and then were kept under running tap water for about $45 \mathrm{~min}$. After that the capsules were rinsed in $0.1 \%(\mathrm{w} / \mathrm{N})$ mercuric chloride solution for $10-12 \mathrm{~min}$ for surface disinfection followed by washing thrice with sterile distilled water. Finally, the capsules were dipped in 95\% ( $\mathrm{v} / \mathrm{N}$ ) ethanol for $60 \mathrm{sec}$ and then kept on sterile Petri dishes for a few minutes to evaporate the last drop of ethanol from the surface of the capsule. After surface sterilization, the capsules were dissected carefully in a laminar air flow cabinet using sterile scalpel and a pair of forceps. The microscopic seeds were taken out aseptically and carefully spread on the surface of the culture medium. For each treatment, three replicate cultures were maintained. The culture vessels with inoculated seeds were incubated at $25 \pm 2^{\circ} \mathrm{C}$ and $10 \mathrm{hrs}$ of photoperiod was provided by Phillips white fluorescent lights of 3000 lux intensity for their germination.

The seed germination media were based on inorganic salts of Knudson $C$ basal medium (KC; Knudson 1946), Modified Knudson C medium (MKC), Murashige and Skoog medium (MS; Murashige and Skoog 1962), Vacin and Went medium (VW; Vacin and Went 1949) and Lindemann medium (LM; Lindemann et al. 1970). In MKC, original iron and micronutrient sources were replaced with those of MS in half strength. All the five media were supplemented with $2 \%(\mathrm{w} / \mathrm{N})$ sucrose. $0.1 \%(\mathrm{w} / \mathrm{v})$ peptone was added separately to all the basal media to observe the effect of organic supplement on seed germination. Vitamin mixture (VIT) was prepared using three vitamins (Nicotinic acid: pyridoxine : thiamine $\mathrm{HCl})$ at $1: 1: 10(1: 1: 10 \mathrm{mg} \Lambda$, respectively). $\mathrm{pH}$ was adjusted at 5.6 and $0.9 \%(\mathrm{w} / \mathrm{N})$ agar (Merck) was added.

After maintaining the cultures for three months, raw data of growth and morphogenesis were collected. Only the healthy seedlings were counted and transferred to fresh medium, while the remaining propagules were scooped out from the medium and every stage of development was counted and recorded carefully. The nongerminated seeds were also counted under the microscope to determine the exact amount of seed inocula. Necrotic propagules were also counted. The emergence of embryo through the ruptured seed testa was considered as the early stage of germination (De Pauw et al. 1995). Germination as well as survival rates of seedlings were expressed through quantitative assessment. Different developmental stages of seedlings such as globular stage and with leaf primordial, seedlings with leafy shoot, with root and expanded leaves were also recorded.

Data were analyzed by one-way ANOVA, followed by DMRT at 5\% significance level. The statistical analysis was performed on arcsine transformed values of the recorded data using SPSS (version16) software package.

\section{Results and Discussions}

Five types of asymbiotic media were tested with different mineral salts at different concentrations, organic supplements and vitamin mixture. No significant difference in 
the rate of seed germination was observed in various media compositions. Previous studies on asymbiotic seed germination of orchids reported the influence of various culture media on seed germination (Sinha and Roy 2000, Mohanty et al. 2012, Pyati 2019, Kang et al. 2020). After establishment of aseptic cultures, it was observed that seed germination was initiated approximately after three weeks in each treatment. The effect of different basal media either singly or along with peptone and vitamin mixture on seed germination and survival of propagules are shown in Fig. 1A,B. Frequency of seed germination was very high in all the treatments without showing any significant differences which ranged from 80 to $89 \%$. The highest rate of seed germination has been noted in LM basal medium (Fig. 1A). It was noted that the seeds of $V$. tessellate germinated in absence of any exogenous PGRs. This might be due to the presence of adequate amount of endogenous growth regulators in the seed tissue which are needed at the initial stage of germination (Hajong et al. 2010, Islam et al. 2014). Specific endogenous growth promoting and inhibiting compounds are directly involved in controlling seed development, dormancy and seed germination (Hartman et al. 1997). It has also been reported that depending upon the choice of culture medium, germination has been affected due to their differences in the balance and supply of organic and inorganic salts (Arditi 1982, Arditi and Ernst 1984, Van Waes and Debergh 1986, Paul et al. 2012).

Though the seed germination frequency was very high in all the treatments, a huge difference was noticed at the same time, when the question of the survival rate of those germinated propagules arose. Although LM basal medium gave maximum frequency of germination, but after germination, the protocorms did not survive, which might be due to the lack of adequate amount of nutrient and/or essential growth stimulating substances (Stoutamire 1974). Maximum frequency of necrosis and death of protocorms was noticed at stage 1 (globular stage). However, fewer cases of protocorm death were noticed at later stages too. This phenomenon is very common in case of seed culture of orchids (Stoutamire 1974, De Pauw et al. 1995, Roy and Banerjee 2002). Of the five seed germination media, maximum survival rate and lowest necrosis were noted in MS with $0.1 \%$ P (Fig. 1B). Maximum seedling survival was recorded in MS $+0.1 \% \mathrm{P}$ which could be due to the presence of nitrogen in the form of ammonium nitrate in the MS medium, whereas in rest of the basal media, nitrogen was present in the form of ammonium sulphate (Paul et al. 2012). In earlier studies, MS was reported as most suitable for seed germination in a number of orchid species like Geodorum densiflorum (Bhadra and Hossain 2003), Vanda teres (Sinha and Roy 2004), Cymbidium findlaysonianum (Tawaro et al. 2008), Dendrobium hookerianum (Paul et al. 2012), Vanda tessellata (Bhattacharjee and Islam 2014, Manokari et al. 2020).

Immediately after germination, the protocorms remained white, without any shoot apex and appeared more or less round (Stage 1: globular stage; Fig. 2B). Subsequently, those quickly turned green and an apical notch was formed which was later developed in to small leaf primordium at the apex (Stage 2: leaf primordial stage; Fig. 2C). Apart from 
apical leaf primordia, the protocorms developed shiny rhizoids at the basal region. Later, leaf primordia expanded to develop leafy shoots (Stage 3: leafy stage; Fig. 2D) which was followed by root induction at the basal region of the protocorm to form complete seedlings (Stage 4: rooted stage: Fig. 2E). These developmental stages are common for most of the orchid species especially for epiphytic orchids (Arditi 1967). Apart from these four developmental stages, two more stages were also recorded during the process of morphogenesis, which are multiple protocorm like bodies and the callus stage. After three months of culture, the seedlings exhibited a number of morphogenetic stages which were eventually been considered as growth parameters (Table 1).

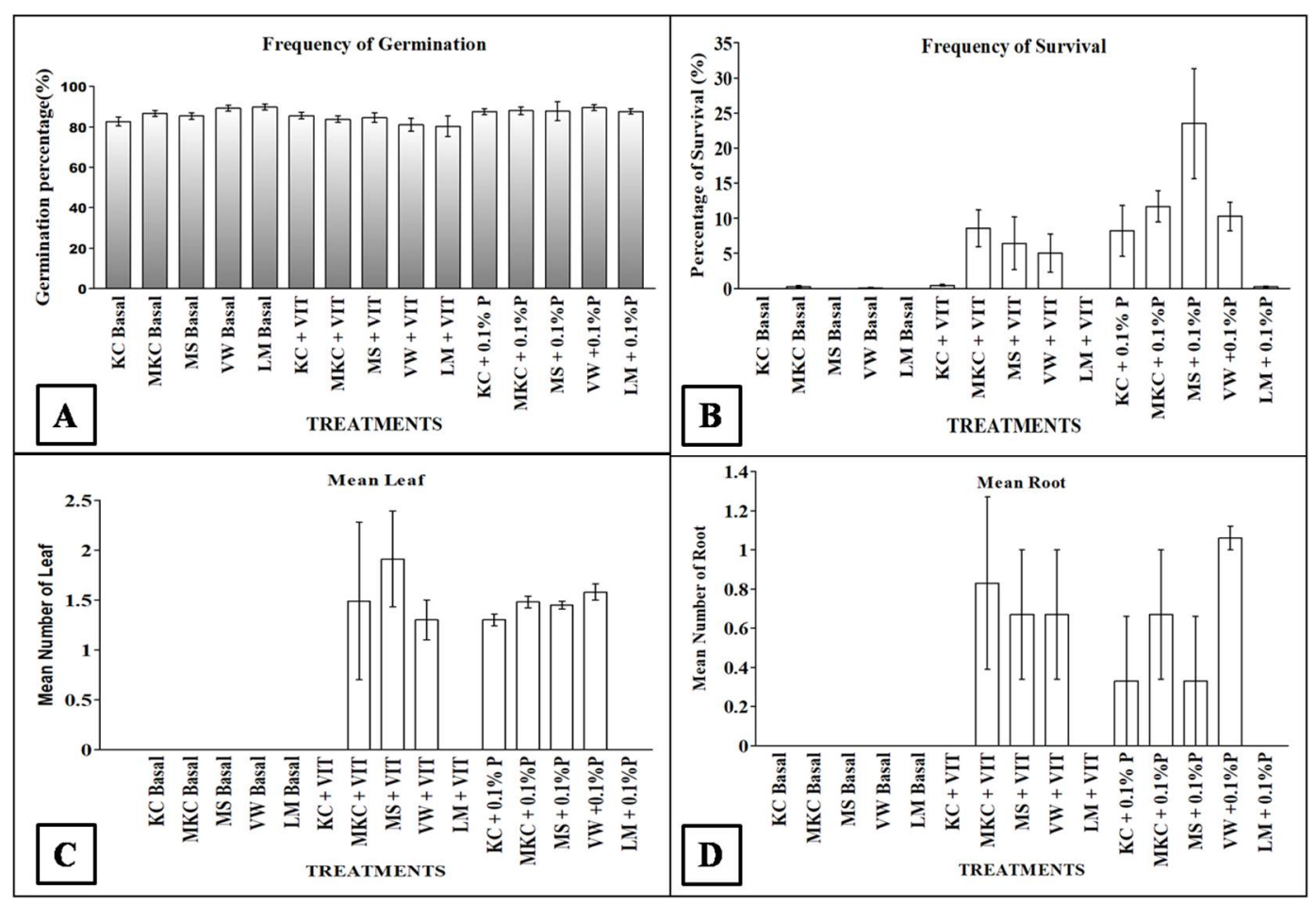

Fig. 1. Different in vitro responses during seed germination of Vanda tessellata: (A) Frequency (\%) of seed germination. (B) Frequency (\%) of survival of germinated protocorms. (C) Mean number of leaves. (D) Mean number of roots in each treatment. [Bar diagram shows the mean value of three replicates of each treatment and the error bar shows standard error occurred during experiment and were plotted using KY plot software].

Although, in the present study germination rate was not optimum in MS, various post germination developmental stages were recorded in the MS $+0.1 \% \mathrm{P}$ medium. In previous studies it was revealed that the ideal formulation for seed germination may not always be the same as that required for protocorm development and plantlet formation 
(Kauth et al. 2008, Koene et al. 2019). In case of media supplementation with peptone, majority of the propagules were restricted at leaf primordial stage in $\mathrm{LM}+0.1 \% \mathrm{P}$ medium. Globular stage protocorms (Stage 1) were only recorded in MS $+0.1 \% \mathrm{P}$ medium as maximum necrosis in all other treatments occurred at globular stage. Leafy stage (Stage 3) and rooted stage (Stage 4) were recorded in all the four media combinations except in LM $+0.1 \%$ P. Leaf primordial stage (Stage 2) was found to be most abundant and was found in all the media combinations (Fig. 2C, Table 1). Apart from these four stages, multiple protocorm like bodies was only recorded in MKC $+0.1 \%$ $\mathrm{P}$ medium. Maximum number of roots was developed in VW $+0.1 \%$ P medium (Fig. 1D).
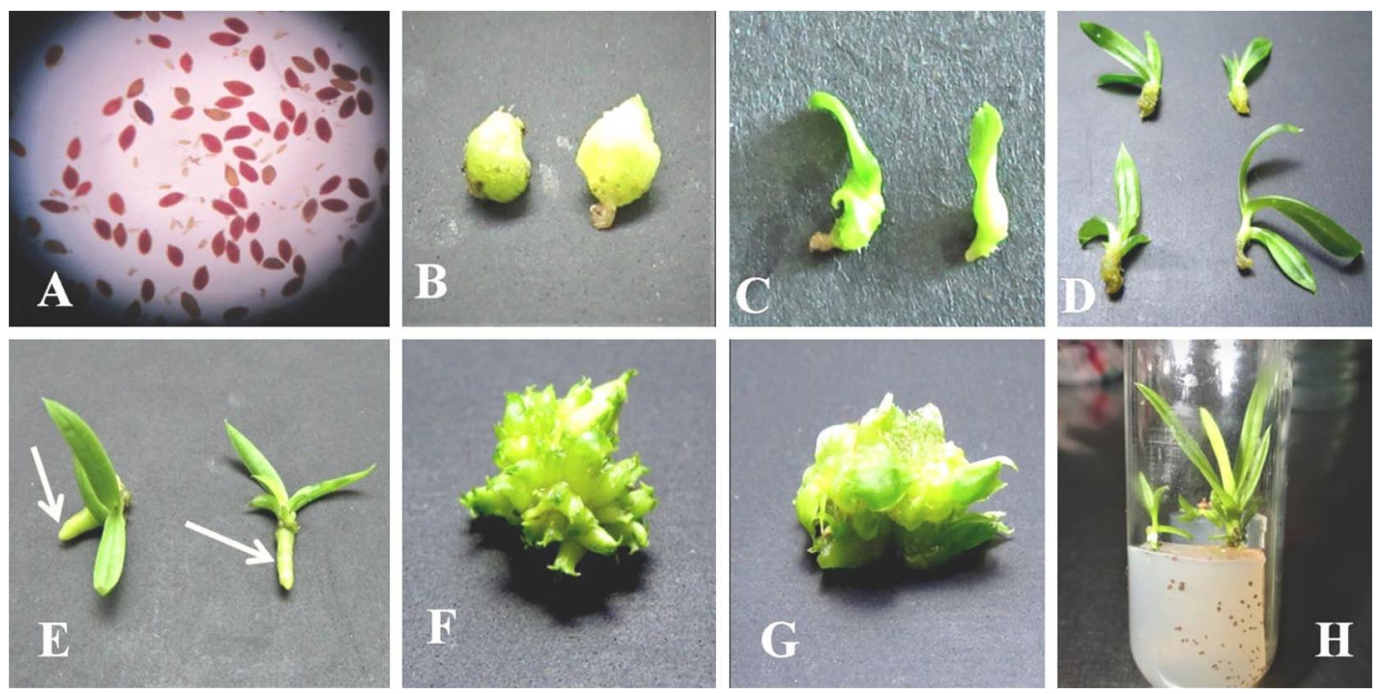

Fig. .2. The seeds and different developmental stages of seedlings of Vanda tessellata: A. TTC treated seeds of V. tessellata. B. Globular stage (Stage 1). C. Leaf primordial stage (Stage 2). D. Leafy stage (Stage 3). E. Rooted stage (Stage 4). F. Multiple protocorm like bodies. G. Callus differentiating into PLBs. H. Rooted plantlets during culture condition.

It is well-established that $\mathrm{NH}_{4}{ }^{+}$and $\mathrm{NO}_{3}{ }^{-}$ions (individually or in combination) are very crucial for in vitro germination of orchid seeds as well as for growth and development of the germinated propagules (Dohling et al. 2008, Poothong and Reed 2016, Zhang et al. 2019). The high rate of germination followed by further protocorm development in MS could be due to the presence of rich source of macro and micro elements (Hossain et al. 2009, Paul et al. 2012, Bhowmik and Rahman 2017). In MS + 0.1\% $\mathrm{P}$ medium, where peptone was added, the survival rate of germinated seedlings was accelerated and the propagules subsequently passed through sequential developmental stages. Similar response was also recorded in case of $\mathrm{MKC}+0.1 \% \mathrm{P}, \mathrm{VW}+0.1 \% \mathrm{P}$ and $\mathrm{KC}$ $+0.1 \% \mathrm{P}$ media except LM $+0.1 \% \mathrm{P}$ (Fig. 1B, Table 1). These results suggest that the nitrogen content of the medium is an important factor for healthy growth and 
development of protocorms. It has been previously reported that, peptone could act as a good source of organic nitrogen and contains about $16.16 \%$ total nitrogen comprising primarily of amino nitrogen as amino acids (Olivia and Arditi 1984, Arditi and Ernst 1993). Thus, addition of $0.1 \%$ peptone would provide additional $161.6 \mathrm{mg} /$ nitrogen into the culture medium (Roy and Banerjee 2002). Therefore, it seems likely that the addition of peptone stimulated the growth of germinated propagules in $\mathrm{KC}+0.1 \% \mathrm{P}, \mathrm{MKC}+0.1 \% \mathrm{P}$, $\mathrm{VW}+0.1 \% \mathrm{P}$, and $\mathrm{MS}+0.1 \% \mathrm{P}$ media. Similar response was recorded in case of Cymbidium giganteum, where peptone was found to be beneficial for increasing seed germination as well as the size of protocorm (Hossain et al. 2010).

Table 1. Effect of different media composition on various developmental stages of germinated protocorms.

\begin{tabular}{|c|c|c|c|c|c|c|}
\hline Treatment & $\begin{array}{l}\text { Globular stage } \\
\% \\
(\text { Stage } 1) \pm \mathrm{SE}\end{array}$ & $\begin{array}{l}\text { Leaf primordial } \\
\text { stage } \% \\
\text { (Stage 2) } \pm \text { SE }\end{array}$ & $\begin{array}{l}\text { Leafy stage } \% \\
(\text { Stage } 3) \pm \mathrm{SE}\end{array}$ & $\begin{array}{l}\text { Rooted } \\
\text { stage } \% \\
(\text { Stage } 4) \pm \mathrm{SE}\end{array}$ & $\mathrm{MPB} \% \pm \mathrm{SE}$ & $\begin{array}{l}\text { Callus stage } \\
\% \pm \text { SE }\end{array}$ \\
\hline KC basal & $0.00 \pm 0.00^{a}$ & $0.00 \pm 0.00^{a}$ & $0.00 \pm 0.00^{a}$ & $0.00 \pm 0.00 \mathrm{a}$ & $0.00 \pm 0.00^{a}$ & $0.00 \pm 0.00^{a}$ \\
\hline MKC basal & $0.00 \pm 0.00^{\mathrm{a}}$ & $100.00 \pm 0.00^{c}$ & $0.00 \pm 0.00^{a}$ & $0.00 \pm 0.00^{\mathrm{a}}$ & $0.00 \pm 0.00^{a}$ & $0.00 \pm 0.00^{a}$ \\
\hline MS basal & $0.00 \pm 0.00^{\mathrm{a}}$ & $0.00 \pm 0.00^{\mathrm{a}}$ & $0.00 \pm 0.00^{a}$ & $0.00 \pm 0.00^{\mathrm{a}}$ & $0.00 \pm 0.00^{\mathrm{a}}$ & $0.00 \pm 0.00^{\mathrm{a}}$ \\
\hline VW basal & $0.00 \pm 0.00^{a}$ & $33.33 \pm 33.33^{\mathrm{ab}}$ & $0.00 \pm 0.00 \mathrm{a}$ & $0.00 \pm 0.00^{a}$ & $0.00 \pm 0.00^{a}$ & $0.00 \pm 0.00^{a}$ \\
\hline LM basal & $0.00 \pm 0.00^{a}$ & $0.00 \pm 0.00^{a}$ & $0.00 \pm 0.00^{a}$ & $0.00 \pm 0.00^{a}$ & $0.00 \pm 0.00^{a}$ & $0.00 \pm 0.00^{a}$ \\
\hline $\mathrm{KC}+\mathrm{VIT}$ & $66.67 \pm 33.33^{b}$ & $33.33 \pm 33.33^{\mathrm{ab}}$ & $0.00 \pm 0.00^{a}$ & $0.00 \pm 0.00^{\mathrm{a}}$ & $0.00 \pm 0.00^{\mathrm{a}}$ & $0.00 \pm 0.00^{\mathrm{a}}$ \\
\hline $\mathrm{MKC}+\mathrm{VIT}$ & $0.00 \pm 0.00^{\mathrm{a}}$ & $66.67 \pm 9.99 b c$ & $13.55 \pm 11.75^{b}$ & $6.09 \pm 3.21^{\mathrm{a}}$ & $13.68 \pm 4.67 c$ & $0.00 \pm 0.00^{\mathrm{a}}$ \\
\hline $\mathrm{MS}+\mathrm{VIT}$ & $2.22 \pm 2.22^{\mathrm{a}}$ & $19.20 \pm 6.71^{\mathrm{ab}}$ & $66.25 \pm 14.92^{\mathrm{d}}$ & $5.66 \pm 3.21^{\mathrm{a}}$ & $2.96 \pm 2.96^{\mathrm{ab}}$ & $3.70 \pm 3.70^{\mathrm{b}}$ \\
\hline VW + VIT & $5.56 \pm 5.56^{\mathrm{a}}$ & $62.28 \pm 2.00^{\mathrm{bc}}$ & $26.43 \pm 0.72^{c}$ & $5.73 \pm 2.88^{\mathrm{a}}$ & $0.00 \pm 0.00^{a}$ & $0.00 \pm 0.00^{\mathrm{a}}$ \\
\hline $\mathrm{LM}+\mathrm{VIT}$ & $0.00 \pm 0.00^{\mathrm{a}}$ & $0.00 \pm 0.00^{\mathrm{a}}$ & $0.00 \pm 0.00^{\mathrm{a}}$ & $0.00 \pm 0.00^{\mathrm{a}}$ & $0.00 \pm 0.00^{\mathrm{a}}$ & $0.00 \pm 0.00^{\mathrm{a}}$ \\
\hline $\mathrm{KC}+0.1 \% \mathrm{P}$ & $0.00 \pm 0.00^{\mathrm{a}}$ & $60.07 \pm 10.11^{\mathrm{bc}}$ & $38.59 \pm 8.79 c$ & $1.33 \pm 1.33^{a}$ & $0.00 \pm 0.00^{\mathrm{a}}$ & $0.00 \pm 0.00^{\mathrm{a}}$ \\
\hline $\mathrm{MKC}+0.1 \% \mathrm{P}$ & $0.00 \pm 0.00^{a}$ & $46.66 \pm 6.76^{\mathrm{ab}}$ & $43.30 \pm 9.13 c$ & $7.31 \pm 5.47 \mathrm{a}$ & $2.72 \pm 1.75^{\mathrm{b}}$ & $0.00 \pm 0.00^{a}$ \\
\hline $\mathrm{MS}+0.1 \% \mathrm{P}$ & $44.67 \pm 18.74^{b}$ & $24.52 \pm 6.77 \mathrm{ab}$ & $26.81 \pm 10.74^{c}$ & $4.00 \pm 4.00^{a}$ & $0.00 \pm 0.00^{a}$ & $0.00 \pm 0.00^{a}$ \\
\hline $\mathrm{VW}+0.1 \% \mathrm{P}$ & $0.00 \pm 0.00^{\mathrm{a}}$ & $40.60 \pm 0.22^{\mathrm{ab}}$ & $41.95 \pm 0.90^{c}$ & $17.45 \pm 1.08^{\mathrm{b}}$ & $0.00 \pm 0.00^{\mathrm{a}}$ & $0.00 \pm 0.00^{\mathrm{a}}$ \\
\hline $\mathrm{LM}+0.1 \% \mathrm{P}$ & $0.00 \pm 0.00^{a}$ & $66.67 \pm 33.33^{\mathrm{bc}}$ & $0.00 \pm 0.00^{a}$ & $0.00 \pm 0.00^{\mathrm{a}}$ & $0.00 \pm 0.00^{\mathrm{a}}$ & $0.00 \pm 0.00^{\mathrm{a}}$ \\
\hline
\end{tabular}

Data shown are the mean of three replicates \pm SE. In each column, mean values followed by the same letter are not significantly different at the $5 \%$ level (DMRT).

Although basal media gave high frequency of germination, it failed to induce further development of germinated propagules. Seeds became necrotic after swelling in the $\mathrm{KC}$, MS and LM basal media. However, in case of MKC and VW basal media, the germinated propagules remained restricted to Stage 2 (leaf primordial stage). The highest frequency of leaf primordial stage was found in MKC basal medium.

Addition of vitamin mixture to the basal media also stimulated the survival rate of germinated propagules and its effect on morphogenesis of the protocorms is clearly 
shown in Table 1. In the presence of vitamin mixture, all the four morphogenetic developmental stages were recorded in VW + VIT and MS + VIT media (Fig. 2 B-E; Table 1). Maximum frequency of globular stage (Stage 1) was observed in KC + VIT medium. On the other hand, frequency of mature leafy stage (Stage 3) was found highest in MS + VIT medium. Apart from these four stages two more types of morphological features were also observed in these set of media. Maximum frequency of multiple protocorm like bodies (MPB) (Fig. 2F) was recorded in MKC + VIT medium, while callus stage (Fig. 2G) was recorded only in MS + VIT medium. Maximum number of leaves was observed in MS + VIT medium (Fig. 1C). Sharma et al. (1991) reported that during seed germination and seedling growth of Coelogyne punctulata and Cymbidium elegans, addition of various vitamins exhibited synergistic effect. On the other hand, thiamine, nicotinic acid and biotin were found most effective in germination and differentiation of Cattleya hybrids (Mariat 1949). In Orchis laxiflora, it was reported that pyridoxine with nicotinic acid and biotin enhanced seed germination process (Mead and Bulard 1979).

All the developmental stages of seedlings were recorded in MS + VIT medium. Maximum frequency of MPB was recorded in MKC + VIT medium. On the other hand, $\mathrm{VW}+0.1 \% \mathrm{P}$ medium was able to produce maximum number of rooted plantlets. Again, MKC $+0.1 \%$ P medium gave satisfactory result in this regard. So, it is not an easy task to recommend a single medium which would be exclusively suitable for seed germination and seedling survival of this particular orchid species. Thus, the primary objective of this study was to produce maximum number of healthy seedlings which in turn could be utilized for in vitro storage and conservation of this species. Therefore, in general MS + VIT, MKC + VIT, MKC + 0.1\% P, VW + VIT and VW + VIT media could be recommended for this purpose instead of a single one. However, of all these, MS + VIT medium might be the optimal one since all the developmental stages were recorded in this particular treatment.

\section{Acknowledgements}

The first author (SA) gratefully acknowledges The University Grants Commission, New Delhi, India for the financial assistance in the form of UGC-BSR fellowship. The authors also express their gratitude to the UGC-DRS and DST-FIST sponsored Department of Botany, Visva-Bharati for providing laboratory facilities to carry out the work.

\section{References}

Abraham S, Augustine J and Thomas TD (2012) Asymbiotic seed germination and in vitro conservation of Coelogyne nervosa A. Rich. An endemic orchid to Western Ghats. Physiol. Mol. Biol. Plants 18(3): 245-251.

Arditti J (1967) Factors affecting the germination of orchid seeds. Bot. Rev. 33: 1-97.

Arditti J (1979) Aspects of the physiology of orchids. In: Wollhouse H (ed) Advances in Botanical Research 7. London, UK, Academic Press. 
Influence of Basal Media, Vitamins and Peptone

Arditti J (1982) Orchid seed germination and seedling culture - A manual. In: Arditti J (ed) Orchid Biology - Reviews and perspectives II. New York, USA, Cornell University Press.

Arditti J and Ernst R (1984) Physiology of germinating orchid seeds. In: Arditti J (ed.) Orchid Biology reviews and perspectives, Vol. III, Ithaca, NY, USA: Cornell University Press, 179-222.

Arditti J and Ernst R (1993) Micropropagation of orchids. John Wiley \& Sons, NY.

Arditti J, Michaud JD and Oliva AP (1981) Seed germination of North American orchids. I. Native Californian and related species of Calypso, Epipactis, Goodyera, Piperia and Platanthera. Bot. Gaz. 142:442-453.

Bhadra SK and Hossain MM (2003) In vitro germination and micropropagation of Geodorum densiflorum (Lam.) Schltr., an endangered orchid species. Plant Tissue Culture 13(2): 165-171.

Bhattacharjee B and Islam SMS (2014) Effects of plant growth regulators on multiple shoot induction in Vanda tessellata (Roxb.) Hook. ex G.Don. an endangered medicinal orchid. Int. J Sci. Nature 5:707-712.

Bhowmik TK andRahman MM (2017) Effect of different basal media and PGRs on in vitro seed germination and seedling development of medicinally important orchid Cymbidium aloifolium (L.) Sw. Journal of Pharmacognosy and Phytochemistry 6(1): 167-172.

De Pauw MA, Remphrey WR and Palmer CE (1995) Thecytokinin preference for in vitro germination and protocorm growth of Cypripedium candidum. Ann. Bot. 75: 267-275.

Dohling S, Kumaria S and Tanden P (2008) Optimization of nutrient requirements for asymbiotic seed germination of Dendrobium longicornu and D. formosum. Proceedings of the Indian National Science Academy 74: 167-171.

Hajong S, Kumaria S and Tandon, P (2010) In vitro propagation of the medicinal orchid Dendrobium chrysanthum. Proceedings of the Indian National Science Academy 76: 1-6.

Hartman HT, Kester DE, Davis FT and Geneve RL (1997) Plant propagation - Principles and practices. Prentice Hall, Upper Saddle River, NJ. pp. 177-215.

Hossain MM, Sharma M and Pathak P (2009) Cost effective protocol for in vitro mass propagation of Cymbidium aloifolium (L.) Sw. - A medicinally important orchid. Eng. Life Sci. 9(6):444-453.

Hossain MM, Sharma M, Teixeria da Silva JA and Pathak P (2010) Seed germination and tissue culture of Cymbidium giganteum Wall. Ex Lindl. Sci. Hortic. 123(4): 479-487. https://doi. org/10.1016/.scienta.2009.10.009

Islam MR, Kabir KMR, Hossain MS, Hossain MF and Khalil MI (2014) Efficient in vitro cultural techniques for seeds germination of Vanda roxburghii. World J. Agric. Sci. 10(4): 163-168.

Kang H, Kang KW, Kim DH and Sivanesan I (2020) In vitro propagation of Gastrochilus matsuran (Makino) Schltr., an endangered epiphytic orchid. Plants. 9(4): 524. doi:10.3390/ plants9040524

Kauth PJ, Kane ME, Vendrame WA and Reinhardt AC (2008) Asymbiotic germination response to photoperiod and nutritional media in six populations of Calapogan tuberosus (Orchidaceae): evidence for ecotypic differentiation. Ann. Bot. 102: 783-293.

Kauth PJ, Vendrame WA and Kane ME (2006) In vitro culture and seedling development of Calopogon tuberosus. Plant Cell Tiss. Org. Cult. 85: 91-102.

Khela S and Chadburn H (2014) Vanda tessellata. The IUCN Red List of Threatened Species 2014: e.T22486461A22488222. https://doi.org/10.2305//UCN.UK.2014-1.RLTS.T2248 6461A 22488 222.en. 
Knudson L (1946) A new nutrient solution for germination of orchid seed.Amer. Orchid Soc. Bull.15:214-217.

Koene FM, Amano É and Ribas LLF (2019) Asymbiotic seed germination and in vitro seedling development of Acianthera prolifera (Orchidaceae). S. Afr. J. Bot. 121: 83-91. https://doi.org/ 10.1016/j.sajb.2018.07.019

Lindemann EG, Gunckel JE and Davidson OW (1970) Meristem culture of Cattleya. Amer. Orchid Soc. Bull.39:1002-1004.

Manokari M, Latha R and Priyadharshini S (2020) Short-term cold storage of encapsulated somatic embryos and retrieval of plantlets in grey orchid (Vanda tessellata (Roxb.) Hook. ex G. Don). Plant Cell Tiss. Org. Cult. Sp. Issue: 1-13 https://doi.org/10.1007/s11240-020-01899-y

Mariat F (1949) Action de l'acidenicotiniquesur la germination et le developement des embryons de Cattleya. Compte Renduhebdomadaire des seances de VAcademie des Sciences, Paris. 229: 1355-1357.

Mead JW and Bulard C (1979) Vitamins and nitrogen requirements of OrchisqlaxifloraLamk.New Phytol.83:129-136.

Mohanty P, Paul S, Das MC, Kumaria S and Tandon P (2012) A simple and efficient protocol for the mass propagation of Cymbidium mastersii: an ornamental orchid of Northeast India. AoB Plants, pls023. doi: 10.1093/aobpla/pls023.

Mukhopadhyay K and Roy SC (1994)In vitro induction of 'runner' - a quick method of micropropagation in orchid. Sci. Hortic. 56: 331-337.

Murashige T and Skoog F (1962) A revised medium for rapid growth and bioassays with tobacco tissue culture. Physiol. Plant. 15: 473-497. doi: 10.1111 j.13993054.1962.tb08052.x.

Oliva AP andArditti J (1984) Seed germination of North American orchids. 11. Native California and Related Species of Aplectrum, Cypripedium and Spiranthes. Bot. Gaz. 145 (4): 495-501.

Pandey NK, Joshi GC and Mudaiya RK (2003) Management and conservation of medicinal orchids of Kumaon and Garhwal Himalaya. In: Singh V, Jain AP (eds) Ethnoboany and medicinal plants of India and Nepal. Scientific, Jodhpur, pp. 114-118.

Paul S, Kumaria S and Tandon P (2012) An effective nutrient medium for asymbiotic seed germination and large-scale in vitro regeneration of Dendrobium hookerianum, a threatened orchid of northeast India. AoB Plants. https ://doi.org/10.1093/aobpl a/plr032

Poothong S and Reed BM (2016) Optimizing shoot culture media for Rubus germplasm: The effects of $\mathrm{NH}^{4+}, \mathrm{NO}^{3-}$, and total nitrogen. In Vitro Cell Dev. Biol. Plant. 52: 265-275.

Prakash B, Bais RT, Singh P and Khan S (2013a) Effect of different $\mathrm{pH}$ on in vitro seed germination of Vanda tessellata (Roxb.) Hook. Ex. G. Don.an endangered medicinal orchid. Adv. Life Sci. Technol. 8:4-7.

Prakash B, Khan S and Bais RT (2013b) Effect of different media on in vitro seed germination and protocorm formation of Vanda tessellata (Roxb.) Hook. ex. G. Don - An endangered medicinal orchid. Researcher. 5(4): 19-22.

Pyati A (2019) In vitro seed germination, protocorm formation and plantlet regeneration in Aeridesringens Fisher. Plant Tiss. Cult. and Biotech. 29: 49-62. https://doi.org/10.3329/ ptcb.v29i1.41978

Rasmussen HN (1995) Terrestrial orchids from seed to mycotrophic plant. Cambridge, UK: Cambridge University Press. 
Roy J and Banerjee N (2002) Rhizome and shoot development during in vitro propagation of Geodorum densiflorum (Lam.) Schltr. Sci. Hortic. 94:181-192.

Sharma SK, Tandon P and Mishra RR (1991) Vitamins as related to axenic seed germination and seedling growth of Cymbidium elegans Lindl. and Coelogyne punctulata Lindl. Journal of Orchid Society, India 5:25-28.

Singh A and Duggal S (2009) Medicinal orchids: An overview. Ethnobot. Leafl. 13: 351-363.

Sinha P and Roy SK (2004) Regeneration of an indigenous orchid Vanda teres (Roxb.) Lindl. through in vitro culture. Plant Tiss. Cult. 14(1): 55-61.

Stewart SL and Kane ME (2006) Asymbiotic seed germination and in vitro seedling development of Habenariam acroceratitis (Orchidaceae), a rare Florida terrestrial orchid. Plant Cell Tiss. Org. Cult. 86:147-158.

Stoutamire W (1974) Terrestrial orchid seedlingns. In: Withner CL (ed.) The orchids: scientific studies. Wiley-Interscience, New York, pp. 101-128.

Subramoniam A, Gangaprasad A, Sureshkumar PK, Radhika J and Arun BK (2013) A novel aphrodisiac compound from an epiphytic orchid that activates nitric oxide syntheses'. Int. J. Impotence Res. 25(6): 212-216. doi:10.1038/jiir.2013.18

Suttle GRL (1996) Commercial laboratory production. In: Trigiano RN, Gray DJ, eds. Plant tissue culture concepts and laboratory exercises. CRC Press, Inc., New York, 331-339.

Tawaro S, Suraninpong P and Chanprame S (2008) Germination and regeneration of Cymbidium findlaysonianum Lindl. on a medium supplemented with some organic sources. Walailak Journal of Science and Technology 5:125-135. 10.2004/wjst.v5i2.83.

Thompson DI, Edwards TJ and Van Staden J (2006) Evaluating asymbiotic seed culture methods and establishing Disa (Orchidaceae) germinability in vitro: Relationships, requirements and first-time reports. Plant Growth Regul. 49:269-284.

Vacin E and Went FW (1949) Some pH changes in nutrient solutions. Bot. Gaz. 110: 605-613.

Van Waes JM and Debergh PC (1986) In vitro germination of some Western European orchids. Physiol. Plant. 67: 253-261.

Zhang K, Wu Y and Hang $\mathbf{H}$ (2019) Differential contributions of $\mathrm{NO}^{3-} \mathrm{NH}^{4+}$ to nitrogen use in response to a variable inorganic supply in plantlets of two Brassicaceae species in vitro. Plant Methods.https ://doi.org/10.1186/s1300 7- 019-0473-1. 